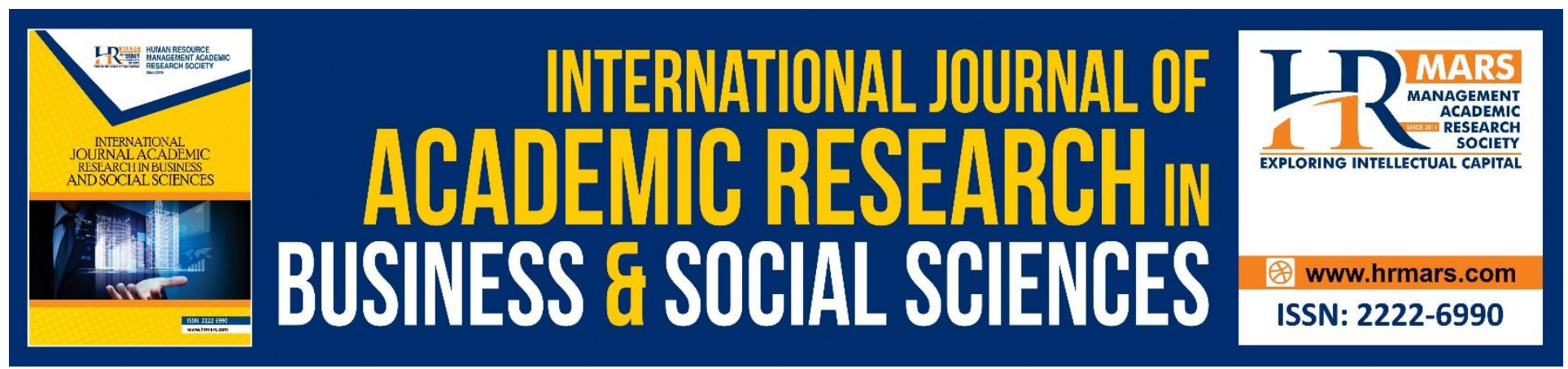

\title{
The Effect of Perceived Value on Sustainable Fashion Consumption in the Era of Covid-19: A Proposed Conceptual Framework
}

Nornajihah Nadia Hasbullah, Zuraidah Sulaiman, Adaviah Mas'od

To Link this Article: http://dx.doi.org/10.6007/IJARBSS/v10-i8/7645

DOI:10.6007/IJARBSS/v10-i8/7645

Received: 09 May 2020, Revised: 12 June 2020, Accepted: 16 July 2020

Published Online: 29 August 2020

In-Text Citation: (Hasbullah, Sulaiman, \& Mas'od, 2020)

To Cite this Article: Hasbullah, N. N., Sulaiman, Z., \& Mas'od, A. (2020). The Effect of Perceived Value on Sustainable Fashion Consumption in the Era of Covid-19: A Proposed Conceptual Framework. International Journal of Academic Research in Business and Social Sciences. 10(8), 895-906.

Copyright: (C) 2020 The Author(s)

Published by Human Resource Management Academic Research Society (www.hrmars.com)

This article is published under the Creative Commons Attribution (CC BY 4.0) license. Anyone may reproduce, distribute, translate and create derivative works of this article (for both commercial and non-commercial purposes), subject to full attribution to the original publication and authors. The full terms of this license may be seen

at: http://creativecommons.org/licences/by/4.0/legalcode

\section{Vol. 10, No. 8, 2020, Pg. 895 - 906}

Full Terms \& Conditions of access and use can be found at http://hrmars.com/index.php/pages/detail/publication-ethics 


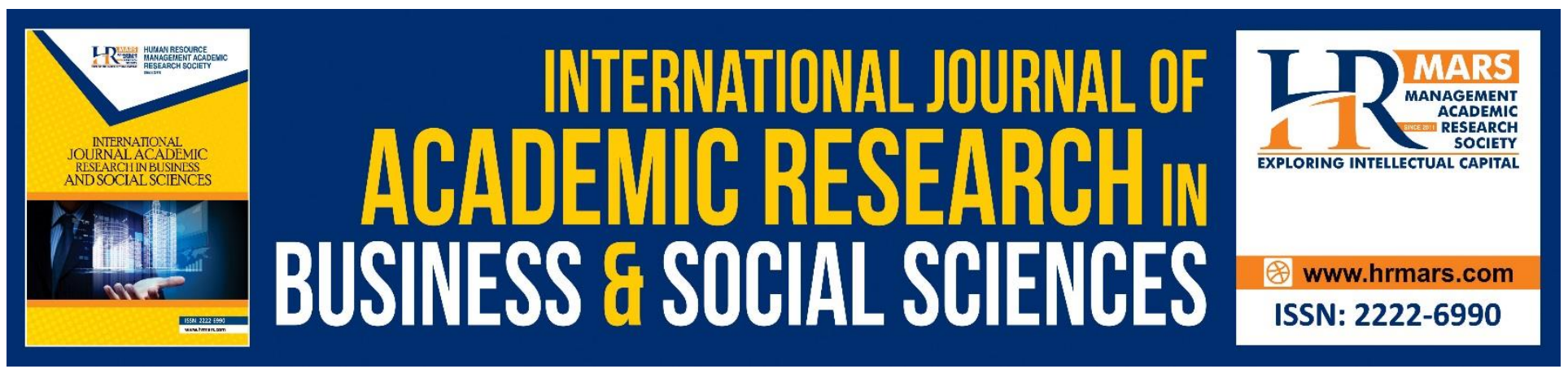

\title{
The Effect of Perceived Value on Sustainable Fashion Consumption in the Era of Covid-19: A Proposed Conceptual Framework
}

\author{
Nornajihah Nadia Hasbullah, Zuraidah Sulaiman, Adaviah Mas'od \\ Azman Hashim International Business School, Universiti Teknologi Malaysia, 81310, Skudai, Johor, \\ Malaysia \\ Email: najihahnadya@yahoo.com.my
}

\begin{abstract}
The outbreak of 2019 Coronavirus Disease (COVID-19) has not only adversely affected the human health, but it has also put a halt to all trades and economy activities. The sustainable fashion business has also been experiencing a similar problem with worldwide quarantine and self-isolation bringing a pause to its production. Nevertheless, COVID-19 is not an excuse to back off from sustainability. On the contrary, this pandemic may add the fuel to the fire and cause the change amongst companies, apart from highlighting the core values both these companies and the products they place before the world. Having that said, this study examined the antecedent of perceived value that is bound to give impact on sustainable fashion consumption. Theoretically, researchers have applied the theory of consumption value to shed light on this positive product after the COVID-19 pandemic has subsided. This theory is composed of five consumption values which include social value, functional value, epistemic value, emotional value and conditional value. Data will be collected from 200 millennial consumers in Malaysia via online survey technique and analysed by using IBM SPSS and SEM PLS.

As far as the authors are concerned, this present study is one of the early attempts to incorporate the antecedent of perceived value that will give impact on sustainable fashion consumption within the Malaysian context in surviving after COVID-19. The expected findings of this present study could help marketers and businesses in parts of targeting, segmenting and positioning sustainable fashion products.
\end{abstract}

Keywords: COVID-19, Sustainable Fashion Consumption, Theory of Consumption Value, Consumption Value, Millennial.

\section{Introduction}

Due to the worsening COVID-19 pandemic plaguing many countries, implementation of lockdown and restricted of movement order is vastly imposed. This movement is carried out purposely for the safety of everyone. One consequence of this current pandemic refers to the deteriorating global economy that leads to the great depression (IMF, 2020). Most industries are 
affected due to the halt of nearly all economic activities and trade (Hakovirta and Denuwara, 2020). One significant industry that has joined the fight again this pandemic is the fashion and textile industry (Razvi, 2020). The initial COVID-19 outbreak has created delays, closures, and disruption in both the manufacturing facilities and supply chains within the fashion industry.

Despite the struggles of the moment, the slow change-embracing fashion industry is witnessing a new paradigm of conscious consumerism in other areas(Fashion Transparency Index, 2020). It seems that COVID-19 has shed light on sustainability issues, which is were further amplified by the ongoing crisis. Sustainability of fashion depends heavily on customer perception as well as on brands to further assert their impact on consumption (Amed et al., 2018). With quarantine and self-isolation, we are no longer being as harmful to the environment, thus inflicting far less harm to Mother Earth and reducing our use of her natural resources (Hakovirta and Denuwara, 2020). We are slowly balancing humanly and ecologically. In this sense, customers across all over the world significantly raise their perceptions of clothing brands during the COVID-19 pandemic, apart from having a positive response when brands have demonstrated social responsibility; returning to communities in need and giving priority to environmental sustainability (La et al., 2020). As the market remains volatile due to COVID-19 and brands struggle to stay committed to these greener and more ethical values, this period calls for greater transparency than ever (Fashion Transparency Index, 2020). With consumers currently unable to interact with brands in person, having in-depth information on supply chain or sustainable practices plays a larger role in the customer's journey, thus the significance of conveying the brand's wider values (Razvi, 2020). After COVID-19, fashion leaders will reshape what it implies to be a sustainable business, together with a unified approach that integrates environmental, social and purchasing considerations into fundamental business practices. With this in mind, sustainable product development can be classified as a one way of innovation.

Literally, surviving this COVID-19 pandemic means sustaining and supporting each other; upholding our values and beliefs while doing the same for others (Zhao et al., 2020). As Malaysia's sustainable fashion development practice is minimal, revisiting core values and link antidote appears to be a challenge (Wai Yee, Hassan and Ramayah, 2016). Besides, there is still lack of theoretical and conceptual work in explaining the core value required for sustainable fashion consumption (Ki and Kim, 2016; De Angelis, Adıgüzel and Amatulli, 2017). In light of the aforementioned discussion, this study builds upon on the theory of consumption value by (Sheth, Newman and Gross, 1991). This theoretical framework is designed purposely to improve the dimension of core values within the context of sustainable fashion consumption, apart from providing several suggestions on how such product can survive post COVID-19 pandemic.

\section{Objectives of the Study}

This present of study is one of the early attempts to incorporate the antecedent of perceived values (social value, functional value, epistemic value, emotional value and conditional value) that will give impact on sustainable fashion consumption within the Malaysian context in surviving after COVID19. The objectives of this study are as follows:

- To investigate the direct significance effect of functional value on sustainable fashion consumption.

- To investigate the direct significance effect of social value on sustainable fashion consumption.

- To investigate the direct significance effect of emotional value on sustainable fashion consumption. 
INTERNATIONAL JOURNAL OF ACADEMIC RESEARCH IN BUSINESS AND SOCIAL SCIENCES Vol. 10, No. 8, 2020, E-ISSN: 2222-6990 @ 2020 HRMARS

- To investigate the direct significance effect of conditional value on sustainable fashion consumption.

- To investigate the direct significance effect of epistemic value on sustainable fashion consumption.

\section{Literature Review \\ Sustainable Fashion}

It is best to describe sustainable fashion as all facets that consist of a variety of labels, including fair-trade certified, custom-made, locally-made, artisan, vegan, vintage, organic, and recycled (Thomas, 2008 ; Henninger et al., 2016; Brismar, 2019). This notion is also known as 'sustainable' if the business is able to adopt certain measures, such as stocking products that are durable, non-toxic, are of sound quality, safe at workplace, consume less resources, and help to lower pollution (Shen et al., 2017). Lundblad and Davies (2016) added this sense of fashion centres on the aspect of alleged health benefits, natural materials, special cuts, and timeless cuts.

\section{Consumption Value Theory}

Consumption values theory advocates that perceived value influences consumers' decision making related to the choice of product type and brand (Sheth et al., 1991). An overall value assessment reflects one's consumption experience and represents a consumer's value assessment (Zeithaml, 1988).This value assessment is an important criterion that must be considered for those making preference judgments towards guiding their consumption choices. The COVID-19 pandemic will in fact ignite the fire to spark improvements in businesses and how they regard both their goods and themselves.

In explaining the aspect of value, this theory is composed of five consumption values for selecting behaviour (Yoo, Divita and Kim, 2013). Such values include functional, social, emotional, epistemic and conditional value (Lin and Huang, 2012). When selecting a product, every value has its own expected result (Gonçalves, Lourenço and Silva 2016). Each value has a different performance while choosing a product (Gonçalves et al., 2016). As for functional value, sustainable fashion product will be evaluated based on key product priorities including quality and durability. Along the same lines, Post-COVID customers will make decisions in part based on confidence and intent, whereby businesses will be judged on how they behaved during the crisis and how they prio ritize sustainability and accountability after the situation is under control (including emotional value).

Next, social value will be assessed based on the suggestions made by peer, friends, and family - part of culture amidst consumers. Meanwhile, the epistemic value touches on environmental knowledge in general and environmental knowledge in light of the fashion industry in precise. Lastly, conditional value is evaluated based on the availability and the offering of sustainable fashion through digital, as well as brick and mortar, medium.

The use of the consumption value theory in the study of consumer behavior is common. Nevertheless, this consumption value theory asserts that the significance of value components is likely to be different from one context to another (Sheth et al., 1991; Sweeney and Soutar, 2001; 
INTERNATIONAL JOURNAL OF ACADEMIC RESEARCH IN BUSINESS AND SOCIAL SCIENCES Vol. 10, No. 8, 2020, E-ISSN: 2222-6990 @ 2020 HRMARS

Teng, 2018).The next subsection explains the survivability of this positive fashion trend amidst the COVID-19 pandemic by probing into the perceived value elements.

\section{Hypotheses Development}

\section{Functional Value and Sustainable Fashion Consumption}

Functional value influences customers' choice. Sheth et al., (1991) believed this interest was the primary factor of product and service selection. Selection of products is synchronised with the perceived utility developed from several choices by evaluating it based on the capability of the product to function and perform well. It is established in the literature that functional value is indeed a driver of sustainable consumption behaviour (Biswas and Roy, 2015; Mohd Suki, 2016; Singh and Pandey, 2018). In practical, people frequently have to consider self-interest against social benefits (Steg, 2015; Campbell and Winterich, 2018). For instance, products with elements of socio-ecological standards are mostly more expensive than those with lower socio-ecological standards (Steg, 2015). Similarly, Ritter et al. (2015) reflected that consumers take their consumption into account both the quality and price. Despite the higher price charged for eco products, customers do not hesitate to purchase because the value offered is worth it. Drawing on the literature of sustainable consumption, customers in Malaysia are unaffected by high price from the stance of functional value and quality (Mohd Suki, 2016). After this COVID-19 pandemic, the crucial factors that demand consideration are quality and durability. In precise, the deteriorating economy and the rising unemployment rate lead consumers to purchase more quality product. Hence, this research proposes a positive relationship between functional value and sustainable fashion consumption.

$\mathrm{H} 1$ : Functional value is positively related to sustainable fashion consumption.

\section{Social Value and Sustainable Fashion Consumption}

Social value relates to the perceived utility arising from the relation between a product or service and one or more social groups, such as demographic, socioeconomic, and cultural aspects (Sheth et al., 1991). This value is associated with recognition and self-image enhancement (Sweeney and Soutar, 2001), affecting the final actions of green consumers (Finch, 2006) .The literature shows that the desire of the Chinese consumers to buy sustainable fashion items has been related to facesaving values (Wei and Jung, 2017). Face replicates one's position in the social structure and network, which functions as value in the Confucian culture. Customers who are more concerned about sense of belonging were more equipped to comply with the norm of their circle and focus more on environmental protection ( Chi and Zheng, 2016). China practices collectivism orientation and effectively shapes the Chinese consumers' subjective norm. These customers are concerned about the products that their close associates recommend (Chi and Zheng, 2016). In line with this finding, consumers in Malaysia are also affected by social value, which has the greatest impact on consumer environmental concerns, as reflected in their purchase of green products (Biswas and Roy, 2015). They were motivated to engage with sustainable consumption, as their psychological need for relatedness affected them. In this fashion, consumers view sustainable consumption in a meaningful way in close relation with other members of their group (Abdulrazak and Quoquab, 2017). Significantly, peer opinion has a vast impact on one's acceptance of eco products and one's impression when acquiring this kind of products (Mohd Suki, 2016). Following this serious COVID-19 pandemic, the execution of social distance has led more businesses to adopt the digital platform. Companies need to be more transparent in promoting their products. Simultaneously, the practice 
INTERNATIONAL JOURNAL OF ACADEMIC RESEARCH IN BUSINESS AND SOCIAL SCIENCES

Vol. 10, No. 8, 2020, E-ISSN: 2222-6990 @ 2020 HRMARS

of user-generated content can build a long-term relationship between consumers and organisations. Hence, companies need to create more creative contents and activities in order to attract more consumers (Hasbullah, Sulaiman and Mas'od, 2020b). Thus, this study hypothesises that social value can promote sustainable fashion consumption after the COVID-19 pandemic.

$\mathrm{H} 2$ : Social value is positively related to sustainable fashion consumption.

\section{Emotional value and Sustainable Fashion Consumption}

Emotional value is the perceived utility derived from the capacity of an alternative to induce emotions or affective states (Sheth et al., 1991). Emotions are commonly believed to arise from a close interaction between customers and brands (Akgün, Koçoğlu and İmamoğlu, 2013). Environmental concern has been hypothesised to positively influence environmental attitude in light of clothing consumption and purchase intention of clothing products made of sustainable fabrics. Based on the findings, it is essential for fast-fashion retailers to be environmentally concerned for the sake of fashion-conscious consumers, as a way to increase their environmental attitude towards clothing consumption and to increase the sales of clothing products made of sustainable fabrics (Yoo, Divita and Kim, 2018). Notably, marketers should accentuate both emotional and experiential aspects during interaction of customer with the brand (Choi, Pos and Magnusson, 2016). The findings indicate that promotional goods can have epistemic, economic and emotional values, while denying significant social and functional values (Yoo et al., 2013). However, within the context of Malaysia, there are regulations practised in light of sustainable consumption. As a result, consumers disregard sustainable choices since only a few communities across the country adopt them. Malaysian consumers are free to practice sustainable consumption and need more external regulations enforcement (Abdulrazak and Quoquab, 2017) . Besides, the philanthropic factor among young consumers in Malaysia is a huge contributor to clothing disposal choices. Pre-loved clothing is often donated to orphanage homes or non-government organisations (NGOs) that offer drop-off recycling bins and doorstep collection service (Wai Yee et al., 2016). Thus, the authorities should therefore encourage successful methods of clothing disposal by concentrating on philanthropic awareness while informing more customers about the benefits of clothing donation. On the basis of this topic, the following is assumed:

H3: Emotional value is positively related to sustainable fashion consumption.

\section{Conditional value and Sustainable Fashion Consumption}

The conditional value relates to the perceived utility of a product or service as a result of a situation or a set of circumstances. This value is gained by the product or service due to physical or social contingencies that can maximize functional or social value (Sheth et al., 1991). Once the value is strongly linked to the use of a good or service, then the conditional value emerges (Wang, Liao and Yang, 2013). Culture and socio-economic factors play a crucial role in shaping the use of green products and services upon on community (Ritter et al., 2015). Since the significantly positive effect of conditional value on the purpose of green buying has been discovered, it will be mandatory to recognize the status attributes green goods have when developing communication messages aimed at young adolescents in major cities. Accordingly, promotional messages must therefore seek to connect sustainable goods mostly with social needs of young consumers ( Awuni and Du, 2016). As 
noted, Malaysia is a developing country rich in ethnic and cultural diversity that exercises an open market through sharing the same green practices specification with the rest of the globe. Malaysia is Southeast Asia's third largest newly industrialized market economy, and ranks 29th in the global. Therefore, similarities or discrepancies between counties to the same construct may substantiate for the renewable market or business management style (Chekima, 2016). Consistent with conditional value, which could be affected by physical or social precedents ( Hur, Yoo and Chung, 2012); more sustainable fashion entrepreneurs have begun joining this emerging trend, inclusive of Kanoe, Nukleur Wear, Zibossa, and Real-M (Hasbullah, Zuraidah and Mas'od, 2020a). At the same time, the new collection points for clothes, such as recycle box and home collection services, have encouraged the rising in clothes-recycling rates (Wai Yee et al., 2016). Accordingly, the hypothesis is therefore suggested as follows:

H4: Conditional value is positively related to sustainable fashion consumption.

\section{Epistemic value and Sustainable Fashion Consumption}

The epistemic value represents the benefit perceived by a good or service that stimulates a passion for knowledge and creates novelty (Sheth et al., 1991). Knowledge is known in the consumer research domain and encourages all levels of decision process. To further describe, the decisions of environmentally friendly users are affected by epistemological value. (Lin and Huang, 2012). The inclusion of elements about a consumer's previous ecological knowledge and use of information can increase the predictive power (Cerri et al., 2018). Consumers' environmental preferences play an important role in environmental protection. In fact, the understanding by customers about CSR activities drives their behavioral intentions (Moraes et al., 2017). Even more importantly, it is essential to include all product-related information on the product labels. The label should be entailed with additional information and benefits of using sustainable fashion that may enhance consumers' knowledge (Oh and Abraham, 2016). The current finding in the sense of Malaysia suggests a relatively positive support for attitudes as a key determinant of the purpose of green purchasing depends on the specific sample sizes and history, time span or geographical location. In general, consumers develop this beneficial environmental disposition subconsciously or instinctively, where they feel morally compelled to protect the ecosystem and avoid further degradation. Another reason for this relationship stems from the exposure of individuals to information about environmental issues, and when confronted with green behavior such as green procurement, would demonstrate a favorable attitude to communicate and apply their experience in these matters (Chekima, 2016). Consequently, the following is hypothesised:

H5: Epistemic value is positively related to sustainable fashion consumption.

\section{Theoretical Framework}

Drawing from the consumption value theory (CVT) (Sheth et al.,1991), this study proposes a theoretical model that analyzes the relationships between perceived values which includes social, function, emotional, epistemic and conditional value with sustainable fashion. This study predicts that all variables would display a positive effect and ultimately generate continuity of sustainable fashion consumption after the COVID-19 outbreak. Figure 1 illustrates the proposed relationships. 
INTERNATIONAL JOURNAL OF ACADEMIC RESEARCH IN BUSINESS AND SOCIAL SCIENCES Vol. 10, No. 8, 2020, E-ISSN: 2222-6990 @ 2020 HRMARS

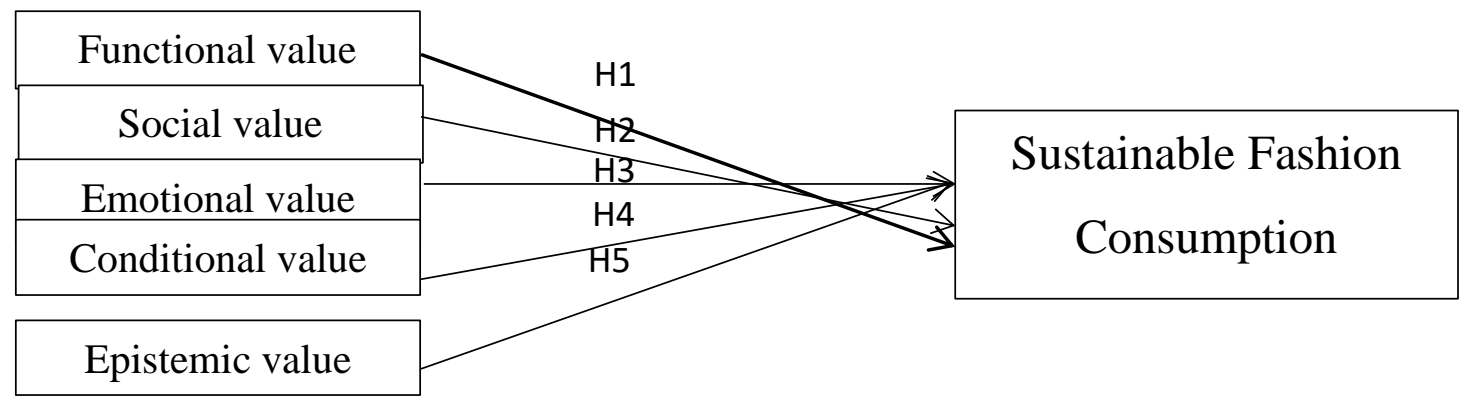

Figure 1: Theoretical Framework of Sustainable Fashion Consumption to strive for post COVID-19.

\section{Methodology}

This study will conduct an online survey to assess the impact of perceived values of consumers on their sustainable fashion consumption, which will help to promote this fashion following the COVID-19 pandemic. The convenience sampling will be executed to select 200 participants in order to complete the survey. The respondents will comprise of the Malaysian Millennial generation aged 21-38 residing in urban areas. Millennials are chosen as respondents because they are described as "agents of change", as well as future users ( Bentley, Fien and Neil, 2004; Tellis and Yin, 2010; Joshi and Rahman, 2017). Two tools, namely IBM SPSS 23.0 and SEM PLS 19.0, will be used to perform the analysis. IBM SPSS will be used to filter data, while SEM PLS will be used as an analytical tool mainly due to its advantage in explaining models with multiple interrelated based relationships (Hair et al., 2017).

\section{Expected Findings}

The expected findings of this study may help marketers and businesses to target, segment and position their sustainable fashion products. All the perceived values are expected to exert a positive impact to sustainable fashion consumption. At present, businesses should be looking at the final value offered, if it is profitable or has an impactful value within the community. Embracing core values has been proven to be a challenge.

\section{Conclusion}

This study seeks to illustrate perceived values by focusing on sustainable fashion consumption among the millennial generation. Drawing on the theory of consumption value (Sheth et al., 1991), entrepreneurs and businesses may gain a clear picture to devise effective strategies and plans to survive after the COVID-19 pandemic. This additional marketing strategy will able to perform well as it shows the value that needs to be highlighted in order to attract customers to purchase sustainable fashion. As a result from this pandemic, not only the fashion industry needs to come together, but the cooperation and support from customers are also essentially needed. Customers are advised to play their roles by treating fashion items as an asset by purchasing sustainable and organic fashion, while buying fewer. It can be manifested that sustainable fashion consumption is a great challenge. In fact, this pandemic obliges us to recognize the interconnections between business, economy, environment and human health. Therefore, effective solution would only be achievable through integration; cooperation and openness are at the forefront of a new paradigm for industry. 
INTERNATIONAL JOURNAL OF ACADEMIC RESEARCH IN BUSINESS AND SOCIAL SCIENCES Vol. 10, No. 8, 2020, E-ISSN: 2222-6990 @ 2020 HRMARS

\section{Theoretical and Contextual Contribution}

The theoretical focus of this study based on theory of consumption value (TCV) (Sheth et al., 1991) which covered five perceived values which includes social, function, emotional, epistemic and conditional value with sustainable fashion. This theory implies an interaction between a customer and product which is essential to be practice especially to survive after COVID-19 pandemic. When customer feels that sustainable fashion practitioner's offering has more value than the non-green product, they will think that their investment is valuable and they will not reluctant to pay more. Significantly, consumers are a smart bunch, so the industry needs to know the customers and find an influencer that's closest to their heart. Landrum (2018) stated that about 70 percent of customers were willingness to pay extra for brands that invest in sustainability. The market share of sustainable product is still lagging as not all customers put their talk into their final action (Jacobs et al., 2018). On top of that, this theory can became a surface or guideline for the companies to devise a viable marketing plan to promote sustainable fashion consumption and to stimuli the development of this fashion. In the long run, the implementation of perceived value will be able to improve the design, develop branding as well as create a competitive advantage.

In part of contextual contribution for this study, it can be seen that, although Malaysia is still in infancy stages, the level of awareness has been increasing and is at a promising level (MATRADE, 2017) . Simultaneously, the global non-profitable organisations, namely fashion revolution campaigns, have already made their move to advocate sustainable, ethical, and fair fashion. The Fashion Revolution movement has already spread across over 100 countries worldwide, including Malaysia. At the same time, some local designers and entrepreneurs also have already jump into this positive movement which includes Real.M; Kanoe; Zibossa; Biji-biji and Kloth Lifestyle (Hasbullah et al., 2020a).

Taken together, this study gives a significant contribution to both theoretical and contextual contribution. The viability of sustainable fashion designs and effective communication strategies from both business and marketing perspectives can ascertain the success of sustainable fashion in Malaysia after this serious pandemic. In fact, sustainability is more than just a current trend; it is all about the future of the next generation.

\section{References}

Abdulrazak, S., \& Quoquab, F. (2017). Exploring Consumers' Motivations for Sustainable Consumption: A Self-Deterministic Approach. Journal of International Consumer Marketing, 30(1), 14-28.

Akgun, A. E., Kocoglu, I., \& Imamoglu, S. Z. (2013). An Emerging Consumer Experience: Emotional Branding. Procedia - Social and Behavioral Sciences, 99, 503-508.

Amed, I., Balchandani, A., Beltrami, M., Berg, A., Hedrich, S., \& Rölkins, F. (2018). The state of fashion 2019. McKinsey\&Company. Retrieved from https://www.mckinsey.com/industries/retail/our-insights/the-state-of-fashion-2019-a-year-ofawakening

Awuni, J. A., \& Du, J. (2016). Sustainable consumption in chinese cities: green purchasing intentions of young adults based on the theory of consumption values. Sustainable Development, 24(2), 124-135. 
INTERNATIONAL JOURNAL OF ACADEMIC RESEARCH IN BUSINESS AND SOCIAL SCIENCES Vol. 10, No. 8, 2020, E-ISSN: 2222-6990 @ 2020 HRMARS

Bentley, M., Fien, J., \& Neil, C. (2004). Sustainable consumption: Young australians as agents of change. Canberra: Department of Family and Community Services.

Biswas, A., \& Roy, M. (2015). Green products: An exploratory study on the consumer behaviour in emerging economies of the East. Journal of Cleaner Production, 87(1), 463-468.

Brismar, A. (2019). Seven forms of sustainable fashion. Retrieved from http://www.greenstrategy.se/sustainable-fashion/seven-forms-of-sustainable-fashion/

Campbell, M. C., \& Winterich, K. P. (2018). A Framework for the Consumer Psychology of Morality in the Marketplace. Journal of Consumer Psychology, 28(2), 167-179.

Cerri, J., Ciappelli, A., Lenuzza, A., Zaccaroni, M., \& Nocita, A. (2018). Recreational angling as a vector of freshwater invasions in Central Italy: perceptions and prevalence of illegal fish restocking. Knowledge \& Management of Aquatic Ecosystems, (419), 38.

Chekima, B. (2016). Consumer Values and Green Products Consumption in Malaysia: A Structural Equation Modelling Approach. In Handbook of Research on Consumerism and Buying Behavior in Developing Nations (pp. 383-408).

Chi, T., \& Zheng, Y. (2016). Understanding environmentally friendly apparel consumption: An empirical study of Chinese consumers. International Journal of Sustainable Society, 8(3), 206227.

Choi, B. H., Pos, A. E., \& Magnusson, M. S. (2016). Emotional change process in resolving selfcriticism during experiential treatment of depression. Psychotherapy Research, 26(4), 484-499.

Darwish, S., Ahmed, U., \& Pahi, M. H. (2020). Innovative work behavior during COVID-19 for medical representative in the pharmaceutical industry: Test of a moderation model in bahrain. International Journal of Pharmaceutical Research. 12(4), 1927-

1934. doi.org/10.31838/ijpr/2020.12.04.277.

De Angelis, M., Adıgüzel, F., \& Amatulli, C. (2017). The role of design similarity in consumers' evaluation of new green products: An investigation of luxury fashion brands. Journal of Cleaner Production, 141, 1515-1527.

Fashion Transparency Index. (2020). Fashion Transparency Index. Retrieved May 13, 2020, from https://issuu.com/fashionrevolution/docs/fr_fashiontransparencyindex2020?fr=sNmI5NzYxM DkOOA

Finch, J. E. (2006). The impact of personal consumption values and beliefs on organic food purchase behavior. Journal of Food Products Marketing, 11(4), 63-76.

Gonçalves, H. M., Lourenço, T. F., \& Silva, G. M. (2016). Green buying behavior and the theory of consumption values: A fuzzy-set approach. Journal of Business Research, 69(4), 1484-1491.

Hair, Joseph, S., M., Ringle, C. M., \& Gudergan, S. P. (2017). Advanced Issues in partial least squares structural equation modeling. SAGE Publications, Inc.

Hakovirta, M., \& Denuwara, N. (2020). How COVID-19 Redefines the Concept of Sustainability. Sustainability, 12(9), 3727.

Hasbullah, N. N., Sulaiman, Z., \& Mas'od, A. (2020a). The Influences of Parasocial Relationship and Sources Credibility in Promoting Sustainable Fashion in Social Network Sites. International Journal of Engineering and Advanced Technology, 9(3), 1642-1648.

Hasbullah, N. N., Sulaiman, Z., \& Mas'od, A. (2020b). User-generated content sources: The use of social media in motivating sustainable luxury fashion consumptions. International Journal of Scientific and Technology Research, 9(3), 5208-5214.

Henninger, C. E., Alevizou, P. J., \& Oates, C. J. (2016). What is sustainable fashion? Journal of 
INTERNATIONAL JOURNAL OF ACADEMIC RESEARCH IN BUSINESS AND SOCIAL SCIENCES Vol. 10, No. 8, 2020, E-ISSN: 2222-6990 @ 2020 HRMARS

Fashion Marketing and Management: An International Journal, 20(4), 400-416.

Hur, W. M., Yoo, J. J., \& Chung, T. L. (2012). The consumption values and consumer innovativeness on convergence products. Industrial Management \& Data Systems.

IMF. (2020). World Economic Outlook Update, June 2020: A Crisis Like No Other, An Uncertain Recovery. Retrieved May 13, 2020, from https://www.imf.org/en/Publications/WEO/Issues/2020/06/24/WEOUpdateJune2020

Jacobs, K., Petersen, L., Hörisch, J., \& Battenfeld, D. (2018). Green thinking but thoughtless buying? An empirical extension of the value-attitude-behaviour hierarchy in sustainable clothing. Journal of Cleaner Production, 203, 1155-1169.

Joshi, Y., \& Rahman, Z. (2017). Investigating the determinants of consumers' sustainable purchase behaviour. Sustainable Production and Consumption, 10, 110-120.

Ki, C. W., \& Kim, Y. K. (2016). Sustainable Versus Conspicuous Luxury Fashion Purchase: Applying Self-Determination Theory. Family and Consumer Sciences Research Journal, 44(3), 309-323.

La, V. P., Pham, T. H., Ho, M. T., Nguyen, M. H., Nguyen, K. L. P., Vuong, T. T., ... Vuong, Q. H. (2020). Policy response, social media and science journalism for the sustainability of the public health system amid the COVID-19 outbreak: The vietnam lessons. Sustainability (Switzerland), 12(7), 2931.

Landrum, N. E. (2018). Stages of corporate sustainability: Integrating the strong sustainability worldview. Organization and Environment, 31(4), 287-313.

Lin, P. C., \& Huang, Y. H. (2012). The influence factors on choice behavior regarding green products based on the theory of consumption values. Journal of Cleaner Production, 22(1), 11-18.

Lundblad, L., \& Davies, I. A. (2016). The values and motivations behind sustainable fashion consumption. Journal of Consumer Behaviour, 15(2), 149-162.

MATRADE. (2017). Export Prospects For Ethical Fashion Industry. Retrieved August 4, 2019, from http://www.matrade.gov.my/en/about-matrade/media/press-releases/3932-exportprospects-for-ethical-fashion-industry

Suki, M. N. (2016). Consumer environmental concern and green product purchase in Malaysia: Structural effects of consumption values. Journal of Cleaner Production, 132, 204-214.

Moraes, C., Carrigan, M., Bosangit, C., Ferreira, C., \& McGrath, M. (2017). Understanding Ethical Luxury Consumption Through Practice Theories: A Study of Fine Jewellery Purchases. Journal of Business Ethics, 145(3), 525-543.

Oh, K., \& Abraham, L. (2016). Effect of knowledge on decision making in the context of organic cotton clothing. International Journal of Consumer Studies, 40(1), 66-74.

Razvi, A. (2020). Standing Together During COVID-19 - Sustainable Apparel Coalition. Retrieved May 13, 2020, from https://apparelcoalition.org/standing-together-during-covid-19/

Ritter, Á. M., Borchardt, M., Vaccaro, G. L. R., Pereira, G. M., \& Almeida, F. (2015). Motivations for promoting the consumption of green products in an emerging country: Exploring attitudes of Brazilian consumers. Journal of Cleaner Production, 106, 507-520.

Shen, L., Shuai, C., Jiao, L., Tan, Y., \& Song, X. (2017). Dynamic sustainability performance during urbanization process between BRICS countries. Habitat International, 60, 19-33.

Sheth, J. N., Newman, B. I., \& Gross, B. L. (1991). Why we buy what we buy: A theory of consumption values. Journal of Business Research, 22(2), 159-170.

Singh, G., \& Pandey, N. (2018). The determinants of green packaging that influence buyers' willingness to pay a price premium. Australasian Marketing Journal, 26(3), 221-230. 
INTERNATIONAL JOURNAL OF ACADEMIC RESEARCH IN BUSINESS AND SOCIAL SCIENCES Vol. 10, No. 8, 2020, E-ISSN: 2222-6990 @ 2020 HRMARS

Steg, L. (2015). Environmental psychology and sustainable consumption. In Handbook of Research on Sustainable Consumption. Edward Elgar Publishing.

Sweeney, J. C., \& Soutar, G. N. (2001). Consumer perceived value: The development of a multiple item scale. Journal of Retailing, 77(2), 203-220.

Tellis, G. J., \& Yin, E. (2010). Consumer innovativeness. In Wiley international encyclopedia of marketing. Chichester, UK: John Wiley \& Sons, Ltd.

Teng, C. I. (2018). Look to the future: Enhancing online gamer loyalty from the perspective of the theory of consumption values. Decision Support Systems, 114, 49-60.

Thomas, S. (2008). From "green blur" to ecofashion: Fashioning an eco-lexicon. Fashion Theory Journal of Dress Body and Culture, 12(4), 525-539.

Wai Yee, L., Hassan, S. H., \& Ramayah, T. (2016). Sustainability and Philanthropic Awareness in Clothing Disposal Behavior Among Young Malaysian Consumers. Sage Open, 6(1).

Wang, H.-Y., Liao, C., \& Yang, L.-H. (2013). What Affects Mobile Application Use? The Roles of Consumption Values. International Journal of Marketing Studies, 5(2), 11.

Wei, X., \& Jung, S. (2017). Understanding Chinese consumers' intention to purchase sustainable fashion products: The moderating role of face-saving orientation. Sustainability (Switzerland), 9(9), 1570.

Yoo, J. J., Divita, L., \& Kim, H. Y. (2018). Predicting consumer intention to purchase clothing products made from sustainable fabrics. Clothing Cultures, 5(2), 211-224.

Yoo, J. J., Divita, L., \& Kim, H. Y. (2013). Environmental awareness on bamboo product purchase intentions: Do consumption values impact green consumption? International Journal of Fashion Design, Technology and Education, 6(1), 27-34.

Zeithaml, V. A. (1988). Consumer perceptions of price, quality, and value: a means-end model and synthesis of evidence. Journal of Marketing, 52(3), 2-22.

Zhao, W., Zhang, J., Meadows, M., Liu, Y., Hua, T., and Fu, B. (2020). A systematic approach is needed to contain COVID-19 globally. Science Bulletin, 65(11), 876-878. 